\section{5

65 \\ OUT OF HOURS PRIMARY PCI IS NOT ASSOCIATED WITH INCREASED ADVERSE OUTCOMES COMPARED TO IN-HOUR PROCEDURES}

K S Rathod, D A Jones, D I Bromage, S M Gallagher, A Mathur, A K Jain, A Wragg, C Knight London Chest Hospital, Bartshealth NHS Trust

doi:10.1136/heartjnl-2013-304019.65

Background Primary percutaneous coronary intervention (PPCI) is the treatment of choice for ST-segment elevation myocardial infarction (STEMI) provided PPCI is performed in a timely manner. There is conflicting data regarding the outcomes of patients treated in-hours versus out of-hours, we sought to determine whether in-hospital and long-term outcomes are different among in-hours versus out of hours PPCI patients.

Methods This was an observational study of 3347 STEMI patients treated with PPCI between 2004 and 2012 at a single centre with follow-up for a median of 3.3 years (IOR range 1.2-4.6 years). The primary end-point was long-term major adverse cardiac events (MACE) with all cause mortality a secondary endpoint. Of these, 1299 patients $(38.8 \%)$ underwent PPCI during a weekday between 08:00 and 18:00 (routine-hours group) and 2048 (61.2\%) underwent PPCI on a weekday between 18:00 and 08:00 or a weekend (out-of-hours group).

Results There were no differences in baseline characteristics between the two groups with comparable door to balloon times (IHs $67.8 \mathrm{~min}$ vs OOHs $69.6 \mathrm{~min}, \mathrm{p}=0.709$ ) and procedural success (table 1). In hospital mortality rates were comparable between the two groups (IHs 3.6\% vs OFHs 3.2\%) with timing of presentation not predictive of outcome (HR 1.25 (95\% CI 0.74 to 2.11). Over the follow-up period there were no significant differences in rates

Table 1

\begin{tabular}{llll}
\hline & $\begin{array}{l}\text { In hours } \\
\text { (n=1299) }\end{array}$ & $\begin{array}{l}\text { Out of hours } \\
\text { (n=2048) }\end{array}$ & p Value \\
\hline Gender (Male) & $74.2 \%$ & $77.1 \%$ & 0.051 \\
Age (years) & $64.02 \pm 14.2$ & $63.16 \pm 14.3$ & 0.126 \\
Hypertension & $39.2 \%$ & $38.3 \%$ & 0.344 \\
Diabetes mellitus & $17.3 \%$ & $17.7 \%$ & 0.424 \\
Hypercholestrolaemia & $30.9 \%$ & $29.7 \%$ & 0.253 \\
Smoking history & $55.6 \%$ & $58.0 \%$ & 0.116 \\
Previous MI & $13.2 \%$ & $11.8 \%$ & 0.156 \\
Previous CABG & $2.6 \%$ & $2.6 \%$ & 0.539 \\
Previous PCI & $9.9 \%$ & $9.6 \%$ & 0.449 \\
Cardiogenic shock & $5.3 \%$ & $6.4 \%$ & 0.113 \\
Ethnicity (Caucasian) & $66.6 \%$ & $64.4 \%$ & 0.226 \\
LVEF & $43.70 \pm 7.5$ & $43.69 \pm 7.5$ & 0.985 \\
CRF (eGFR <60) & $18.5 \%$ & $17.9 \%$ & 0.227 \\
\hline
\end{tabular}




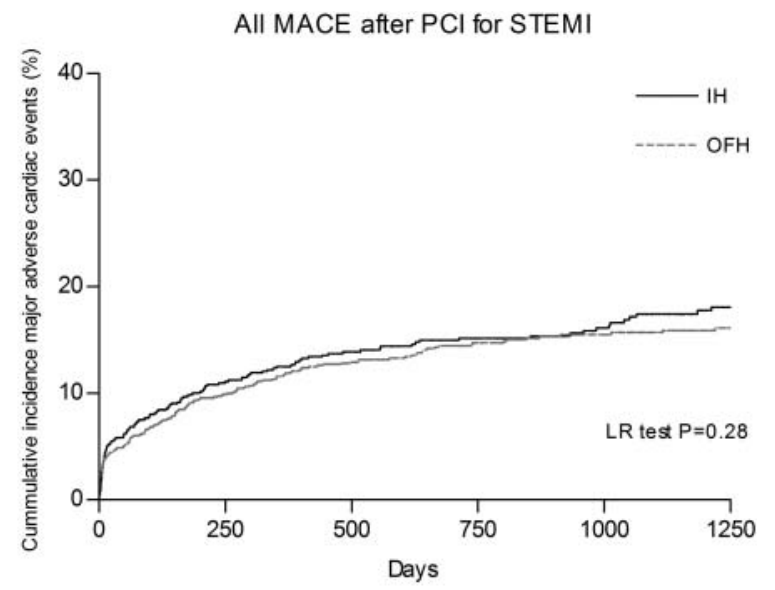

Numbers at risk

$\begin{array}{lllllll}\text { IH } & 1299 & 661 & 523 & 427 & 335 & 231\end{array}$

Figure 1

of mortality (IHs $7.4 \%$ vs OFHs $7.2 \%, \mathrm{p}=0.44$ ) or MACE (IHs $15.4 \%$ vs OFHs $14.1 \%, p=0.28$ ) (figure 1 ) between the two groups. After adjustment for confounding variables using multivariate analysis, timing of presentation was not an independent predictor of mortality (HR 1.04 95\% CI 0.78 to 1.39).

Conclusions This large registry study demonstrates that in a large volume, well-staffed centre, PPCI outside routine-working hours is safe with no difference in outcome compared with PPCI during routine-working hours. 